\title{
Major depression and household food insecurity among individuals with multidrug-resistant tuberculosis (MDR-TB) in South Africa
}

\author{
Andrew Tomita ${ }^{1,2} \cdot$ Suvira Ramlall ${ }^{3}$. Thirusha Naidu ${ }^{4}$. Sbusisiwe Sandra Mthembu ${ }^{5} \cdot$ Nesri Padayatchi $^{6}$. \\ Jonathan K. Burns ${ }^{3,7}$
}

Received: 13 July 2018 / Accepted: 4 February 2019 / Published online: 13 February 2019

(c) The Author(s) 2019

\begin{abstract}
Purpose Household food insecurity in South Africa is a pervasive public health challenge. Although its link to chronic health conditions is well established, its relationship to mental illness, particularly major depression, is not well-understood. Despite KwaZulu-Natal Province being the epicenter of the drug-resistant tuberculosis (MDR-TB) epidemic, and having the largest share of poverty in South Africa, this relationship remains unexamined. This study investigated the association between major depressive episode (MDE) and household food insecurity among individuals with MDR-TB.

Methods We enrolled and interviewed 141 newly admitted microbiologically confirmed MDR-TB inpatients at a specialized TB hospital in KwaZulu-Natal Province, South Africa. Logistic regression models were fitted to assess the relationship between MDE and household food insecurity, while accounting for socio-demographic status (e.g., age, gender, education, marital status, social grant status, income, and preference for living in one's community).

Results The prevalence of MDE and household food insecurity was $11.35 \%$ and $21.01 \%$, respectively. MDE was significantly associated with household food insecurity (aOR 4.63, 95\% CI 1.17-18.38). Individuals who are female (aOR 6.29, 95\% CI 1.13-35.03), young (aOR 8.86, 95\% CI 1.69-46.34), have low educational attainment (aOR 6.19, 95\% CI 1.70-22.59) and receive social grants (aOR 7.60, 95\% CI 2.36-24.48) were most at risk of household food insecurity.

Conclusions MDE in individuals with MDR-TB was significantly associated with household food insecurity, independent of socio-economic status. Although MDR-TB is not exclusively a disease of the poor, individuals from socio-economically disadvantaged backgrounds (e.g., female, young adults, low education, and social grant recipients) were more likely to experience household food insecurity. Our study underscores the need to address the co-occurring cycles of food insecurity and untreated MDE in South Africa.
\end{abstract}

Keywords Food insecurity · Drug-resistant tuberculosis · Depression · South Africa

Andrew Tomita

tomita@ukzn.ac.za

$1 \quad$ KwaZulu-Natal Research Innovation and Sequencing Platform (KRISP), College of Health Sciences, University of KwaZulu-Natal, Durban, South Africa

2 Centre for Rural Health, School of Nursing and Public Health, University of KwaZulu-Natal, Private Bag X7, Congella, Durban 4013, South Africa

3 Department of Psychiatry, University of KwaZulu-Natal, Durban, South Africa
4 Department of Behavioural Medicine, University of KwaZulu-Natal, Durban, South Africa

5 Wentworth Hospital, KwaZulu-Natal Department of Health, Durban, South Africa

6 MRC HIV-TB Pathogenesis and Treatment Research Unit, Centre for the AIDS Programme of Research in South Africa (CAPRISA), Durban, South Africa

7 Institute of Health Research, University of Exeter, Exeter, UK 


\section{Introduction}

Despite the political advances in South Africa since the transition to democracy, there has been little progress in addressing household food insecurity (21.3\% in 2017 versus $21.2 \%$ in 2011 [1]). Food security, defined as access by all people at all times to enough food for an active and healthy life [2], is a cornerstone of development [3], and an indispensable part of well-being [4], including mental well-being $[5,6]$. Food insecurity is a quintessential symbol of poverty, with an increasing proportion of South Africans living under the food poverty line (25.2\% in 2015 versus $21.4 \%$ in 2011 [7]). KwaZulu-Natal (KZN) Province has the second largest population in South Africa (11.4 million people in 2018 [8]), with a high unemployment rate of $40.9 \%$ (in 2018) [9], and a secondary education level of $68.2 \%$ (in 2016) [10]. Many households continue to experience severe food inadequacy, standing at $4.8 \%$ (in 2017) [1], while 34.3\% (in 2015) [7] live under the food poverty line.

Tuberculosis (TB), with 380 new cases per 1000 in 2016, is the leading cause of death in South Africa [11], and can be marginalizing, with numerous social and health consequences. Individuals with TB are often stigmatized [12] by peers (e.g., rejected by partners), within households (e.g., expulsion from homes) and at work (e.g., loss of employment). TB-stigma hampers health-seeking behavior [13], treatment initiation [14], and adherence to care [15], with potential consequences for the emergence of highly resistant strains to the standard antimicrobial isoniazid/rifampicin treatments. Incidence rates of TB and multidrug-resistant tuberculosis (MDR-TB) are 567 (includes HIV + TB) and 25 per 100,000 population, respectively [16], with the disease accounting for the largest percentage of total mortality in $2016(6.5 \%)$ in South Africa [17]. According to the Global Burden of Disease Study 2015, TB is the fifth leading cause of years of life lost [18] and disability-adjusted life-years in South Africa [19]. With an estimated $30.9 \%$ case fatality rate [20], MDR-TB is, in some cases, virtually untreatable and deadly, which further exacerbates the downward cycle of TB-stigma and poor treatment adherence. In KZN, the prevalence of MDR-TB was 2.9\% during 2012-2014 [21], and continues to be a major public health challenge.

Given the serious nature of the disease, exposure to MDR-TB can be a psychologically devastating and lifealtering experience in the absence of adequate support mechanisms [22], posing a long-term threat to essential human security, particularly food security. In South Africa, the lack of mental health support is concerning, with only $25 \%$ of individuals with mental disorders having received treatment within a 12-month period [23]. KZN is the epicenter of the country's MDR-TB epidemic, and has the largest share of poverty in South Africa (24.4\%) in 2015 [7], as well as a high mental health treatment gap of approximately $80 \%$, according to one estimate [24]. Although there are few quantitative estimates for South Africa, the treatment gap for major depression can range from 79 to $93 \%$ for low- and middle-income countries [25]. The estimated prevalence of (current) MDE in South Africa is $4.9 \%$ [26], while workplace-related economic loss due to depression is also estimated to be $4.9 \%$ of gross domestic product [27]. The treatment gap for depression co-morbid with HIV has been cited as a serious challenge [28].

According to several systematic reviews, the link between mental illness and food insecurity is well-documented globally $[5,6]$, but a significant gap in research remains that is relevant to the challenges endured by individuals with MDRTB in Saharan Africa. In this current study, we investigated the role of MDE in household food insecurity among individuals with MDR-TB in KZN. This investigation was driven by a conceptual framework that posits that the link between food insecurity and chronic disease is a cyclic/bi-directional phenomenon [29]. Based on this framework and the notion of social drift which posits that clinical features in mental illness contribute to a downward socio-economic trajectory [30], and guided by previous works [31-33] that investigated the impact of depression as a predictor, we hypothesized that major depression among individuals with MDR-TB poses a "health shock" that contributes to household food insecurity.

\section{Methods}

\section{Study design and participants}

We prospectively enrolled and interviewed those with microbiologically confirmed MDR-TB who were consecutively admitted to a referral-based specialized TB hospital in KZN between September 2015 and October 2016. The inclusion criteria were consenting adult individuals (defined as aged 21-59 years) with no prior history of MDR-TB treatment. This study utilized data from an investigation that monitored neurocognitive impairment in participants with MDR$\mathrm{TB}$, requiring basic literacy to participate in the assessment and excluding individuals $(n=90)$ without primary school level education. Ethical approval was obtained from the University of KwaZulu-Natal's Biomedical Research Ethics Committee. Five potential study participants refused to be involved in the investigation, and written informed consent was obtained from all others. Trained study personnel obtained socio-demographic data and administered the standardized questionnaire (including Household Food Insecurity Access Scale) through a face-to-face structured 
interview. Information on participants' HIV status was obtained from the National Health Laboratory Service based at the study site.

\section{Household food insecurity}

The outcome of the study was household food insecurity, which was measured using the Household Food Insecurity Access Scale version 3 [34]. As a widely used scale in developing countries, including studies in KZN with [35] and without HIV [36-38], HFIAS consists of a culturally invariant set of nine questions covering three domains related to household food insecurity: (1) anxiety/uncertainty about food supply, (2) altering quality of the diet, and (3) insufficient food intake. The response to each question was based on four choices (no $=0$, rarely $=1$, sometime $=2$, often $=3$ ). The composite scores were classified into food secure, insecure without hunger, with moderate hunger, and with severe hunger, according to the scoring guideline [34]. As the instrument pertains to food insecurity in the preceding 30 days, HFIAS was only administered to newly admitted study participants with less than a month of inpatient stay.

\section{Major depressive episode}

Major depressive episode (MDE) was the main covariate of our study and was diagnosed using the Mini International Neuropsychiatric Interview version 6.0 (MINI 6.0) [39], a structured diagnostic schedule utilizing DSM-IV criteria. Research assistants underwent training by a South African psychiatrist for the MINI. In addition to HFIAS and MINI, socio-demographic information (e.g., gender, age, education, marital status, income categories and social grant status) was obtained through face-to-face interviews. We also collected (and included for analysis) data on preference in community residence, given its relevance to MDR-TB treatment [40].

\section{Data analysis}

The analysis consisted of two components: first, descriptive statistics summarized the participants' socio-demographic and clinical status. Second, logistic regression models were fitted to assess the association between MDE and household food insecurity while adjusting for socio-demographic and clinical status. We generated a final outcome measure that combines mild to severe insecurity categories to classify household food insecurity to fit the logistic regression models. STATA 15 was used for the analyses, with the model fit being assessed using the Akaike's Information Criterion [41], where the lower values indicate a better fit.

\section{Results}

\section{Socio-demographic and clinical status}

The socio-demographic characteristics of the 141 MDR-TB study participants are presented in Table 1. Highlighting some results: most study participants were female $(n=110$;

Table 1 Socio-demographic status and clinical profiles of MDR-TB study participants $(N=141)$

\begin{tabular}{|c|c|c|}
\hline & \multicolumn{2}{|c|}{ Overall } \\
\hline & $n$ & $\%$ \\
\hline \multicolumn{3}{|l|}{ Gender } \\
\hline Female & 110 & 78.01 \\
\hline Male & 31 & 21.99 \\
\hline \multicolumn{3}{|l|}{ Age category } \\
\hline $21-29$ & 47 & 33.33 \\
\hline $30-39$ & 55 & 39.01 \\
\hline $40+$ & 39 & 27.66 \\
\hline \multicolumn{3}{|l|}{ Education } \\
\hline$<$ Grade 12 & 72 & 51.06 \\
\hline$\geq$ Grade 12 & 69 & 48.94 \\
\hline \multicolumn{3}{|l|}{ Marital status } \\
\hline Married/stable partner & 81 & 57.45 \\
\hline Casual partner & 14 & 9.93 \\
\hline No relationship/partner & 46 & 32.62 \\
\hline \multicolumn{3}{|l|}{ Income categories } \\
\hline Less than R1000 per month ${ }^{\mathrm{a}}$ & 89 & 63.12 \\
\hline Greater or equal to R 1000 per month & 52 & 36.88 \\
\hline \multicolumn{3}{|l|}{ Social grant income } \\
\hline No & 100 & 70.92 \\
\hline Yes & 41 & 29.08 \\
\hline \multicolumn{3}{|c|}{$\begin{array}{l}\text { Preference for continued living in one's cur- } \\
\text { rent community }\end{array}$} \\
\hline Strong/moderate preference to stay & 107 & 75.89 \\
\hline No preference & 25 & 17.73 \\
\hline Strong/moderate preference to leave & 9 & 6.38 \\
\hline \multicolumn{3}{|l|}{ HIV status } \\
\hline Positive & 124 & 87.94 \\
\hline Negative & 17 & 12.06 \\
\hline \multicolumn{3}{|l|}{ Major depression } \\
\hline No & 125 & 88.65 \\
\hline Yes & 16 & 11.35 \\
\hline \multicolumn{3}{|l|}{ Food insecurity ${ }^{b}$} \\
\hline Food secure & 109 & 78.99 \\
\hline Insecure without hunger & 3 & 2.17 \\
\hline Moderate hunger & 6 & 4.35 \\
\hline Severe hunger & 20 & 14.49 \\
\hline
\end{tabular}

${ }^{\mathrm{a}}$ The upper poverty line for South Africa was R992 in 2015 [42]

${ }^{\mathrm{b}}$ Three missing response in HFIAS 
$78.01 \%$ ), black ( $n=137 ; 97.16 \%)$, and had not completed secondary level education $(n=72 ; 51.06 \%)$. The prevalence of household food insecurity was $21.01 \%(n=29)$, with approximately a third receiving a social grant $(n=41$; $29.08 \%)$. The overwhelming majority were $\operatorname{HIV}+(n=124$; $87.94 \%$ ), and the proportion meeting MDE diagnostic criteria was $11.35 \%(n=16)$.

\section{Association between MDE and household food insecurity}

The results of the regression analysis are indicated in Table 2. The odds of household food insecurity, according to our final model (labeled model 2), were significantly higher [adjusted odds ratio $(\mathrm{aOR})=4.63,95 \%$ CI $1.17-18.38$ ] in individuals with MDE (compared to those without MDE). Examination of other covariates from the same model indicated that the odds of household food insecurity were significantly higher among those who were female (aOR 6.29, 95\% CI 1.13-35.03), in the youngest age group (aOR 8.86, 95\% CI 1.69-46.34), had low educational attainment (aOR $6.19,95 \%$ CI 1.70-22.59) and were in receipt of a social grant (aOR 7.60, 95\% CI 2.36-24.48). The strong moderate preference for continuing to live in one's current community was associated with lower odds of insecurity, but was not statistically significant $(p=0.06)$. The Akaike's Information Criterion (AIC) of the full model (model 2) was 124.23. Although model fit value of model 1 was lower, the significance of MDE under both models remain the same. The model 2 was retained and its findings reported due to the potential importance of income in our study.

\section{Discussion}

The purpose of this study was to examine the association between major depressive episode and household food insecurity among individuals with MDR-TB from an area considered to be at the forefront of the outbreak in sub-Saharan Africa. Two important points emerged from our investigation. First, we found the proportion of severe food insecurity $(14.49 \%)$ in individuals with MDR-TB to be markedly higher than that in the general South African population (4.8\%) [1]. Second, the results of our study suggest an independent association between MDE and household food insecurity in this sample population, even after controlling for important measures of socio-economic status. Our study has also shown considerable gendered (i.e., female) and socioeconomic dimensions (i.e., young, poorly educated, and in receipt of social grant) relating to food insecurity in South Africa.

Our main finding is consistent with various investigations $[32,33,43-46]$, which found that depression/depressive
Table 2 Adjusted logistic regression analysis results on the association between major depression and household food insecurity

\begin{tabular}{|c|c|c|c|c|}
\hline & \multicolumn{2}{|l|}{ Model 1} & \multicolumn{2}{|l|}{$\begin{array}{l}\text { Model } 2 \\
\text { (final) }\end{array}$} \\
\hline & $\mathrm{aOR}$ & SE & $\mathrm{aOR}$ & SE \\
\hline \multicolumn{5}{|l|}{$\begin{array}{l}\text { Major depression } \\
{[\mathrm{No}]}\end{array}$} \\
\hline Yes & $4.16 * *$ & 2.86 & $4.63 * *$ & 3.26 \\
\hline \multicolumn{4}{|l|}{ Gender } & [Male] \\
\hline Female & $5.59 * *$ & 4.77 & $6.29 * *$ & 5.51 \\
\hline \multicolumn{4}{|l|}{ Age category } & \\
\hline $21-29$ & $7.67 * * *$ & 6.43 & $8.86 * * *$ & 7.48 \\
\hline $30-39$ & 2.28 & 1.8 & 2.08 & 1.63 \\
\hline \multicolumn{5}{|l|}{ Education } \\
\hline$<$ Grade 12 & $\mathbf{5 . 0 7} * * *$ & 3.06 & $6.19 * * *$ & 1.09 \\
\hline \multicolumn{5}{|l|}{ Marital status } \\
\hline Casual partner & 1.31 & 1.17 & 1.51 & 1.37 \\
\hline No relationship/partner & 0.95 & 0.57 & 0.98 & 0.59 \\
\hline \multicolumn{5}{|l|}{$\begin{array}{l}\text { Preference for continued living in } \\
\text { one's current community }\end{array}$} \\
\hline Strong/moderate preference to stay & 0.31 & 0.20 & 0.30 & 0.19 \\
\hline Strong/moderate preference to leave & 0.93 & 1.06 & 0.88 & 0.97 \\
\hline \multicolumn{5}{|l|}{$[\mathrm{No}]$} \\
\hline Yes & $\mathbf{6 . 8 3} * * *$ & 3.98 & $7.60 * * *$ & 4.54 \\
\hline \multicolumn{5}{|l|}{$\begin{array}{l}\text { [Greater or equal to R1000 per } \\
\text { month] }\end{array}$} \\
\hline Less than R1000 per month & & & 1.85 & 1.27 \\
\hline \multicolumn{5}{|l|}{ Model fit } \\
\hline AIC & 123.04 & & 124.23 & \\
\hline
\end{tabular}

$* * p<0.05, * * * p<0.01$. Above analysis based on $n=138$ due to HFIAS. Reference group in bracket

symptomatology had a significant effect on household food insecurity. Our investigation on food insecurity was based on the notion of 'health shocks' [47], which is mainly found in the health/labor economics literature. Health shocks place the dual financial burden on individuals to bear the costs of medical treatment and income loss [48] due to under/unemployment. The length of inpatient stay for MDR-TB in South Africa may last 3-6 months (if not longer, until confirmed to be non-infectious [49]), while a major depressive episode (MDE) may become a chronic illness that requires life-long pharmacotherapeutic intervention and psychotherapy [50]. MDR-TB and/or MDE, therefore, places undue economic hardship on many affected persons, with their negative 
economic effects being particularly pronounced among the socio-economically vulnerable who have limited coping resources (e.g., social protection).

Notably, many studies about the role of depression and food insecurity have been conducted among vulnerable and marginalized groups, such as pregnant women [32, 33, 43], young people from informal settlements [51], the economically challenged elderly [44], low-income first-time mothers [45], and HIV + individuals with substance use challenges [46]. In our results, we found that being socio-economically disadvantaged (e.g., female, young adult, low education, and social grant recipient) was a significant correlate of food insecurity. In the light of these findings, we thus argue, as one plausible explanation, that the added burden of MDE exacerbates the vulnerability of MDR-TB in a social drift towards eventual food insecurity.

The 12-month prevalence of MDE in our MDR-TB sample $(11.35 \%)$ was higher than the South African general population estimate of $4.9 \%$ [26]. However, our estimate was lower than the prevalence of depressive episodes among individuals with TB reported from the World Health Survey $(23.7 \%)$ (derived from community-based data from 48 low- and middle-income countries) [52]. It is possible that the lower than expected rate of depression in our study may relate to the fact that our participants were a clinical rather than community sample. Our study participants were receiving intensive inpatient treatment for MDR-TB at a specialized TB hospital, which may have had a positive impact on their depressive symptomatology.

The limitations of the investigation are the cross-sectional and modest sample size associated with our study design, which precludes any causal inference about the effect of depression on food insecurity. Our study is theory-driven (i.e., "health shock" among the socially marginalized), but we also acknowledge the possibility of reverse causation (effect of food security on depression), a point also considered in a recent study from KZN that found a significant association between food insecurity and depression among refugee and migrants [53]. As noted by others [54], and based on our literature review, a growing body of evidence implicitly assumes that food insecurity impacts on health, rather than the reverse. A stronger case for causal inference/temporal order, whether the main study predictor was depression or household food insecurity, requires a longitudinal investigation. Ideally, establishing a bidirectional link between food insecurity and depression would require an analytical model, such as structural equation modeling, which was not possible in this study due to the limited sample size [55]. Further, we acknowledge that the inpatients who were extremely ill due to MDR-TB (which may also be linked to depression, cognitive impairment and substance use) may not have participated in our investigation, thereby limiting generalization of our results. Finally, we did not have data on employment status of our inpatient sample which is a limitation as receipt of a social grant is not a proxy for unemployed status.

Notwithstanding the limitations, the significant association between depression and food insecurity among people with MDR-TB highlights the multifaceted health and social challenges that affected individuals who undergo in a setting considered to be at the epicenter of the MDR-TB epidemic in sub-Saharan Africa. Our current study comes at a time when such complex development challenges are further complicated by the growing threat to food security due to climate change in South Africa [56]. This will require sustainable livelihood approaches in research that not only focuses on food production, but also emphasizes factors that influence people's food accessibility and utilization, such as poverty and health [57]. To our knowledge, there are few studies of MDR-TB in sub-Saharan Africa with a strong mental health component that includes a diagnosis of mental disorder. Our study underscores the need to end the cycle of food insecurity and chronic disease (MDE and MDR-TB) by providing sufficient social protection to buffer against health shocks, as well as accessible high-quality mental health care services for the socially disadvantaged populations of South Africa.

Funding The corresponding author was supported by SA MRC Flagship grant (MRC-RFAUFSP-01-2013/UKZN HIVEPI). Data collection of the study was supported by National Institutes of Health Research Training Grant (R25TW009337), funded by the Fogarty International Center and the National Institute of Mental Health. This study forms part of the Sustainable and Healthy Food Systems (SHEFS) programme supported by the Wellcome Trust's Our Planet, Our Health programme (Grant number 205200/Z/16/Z). The content is solely the responsibility of the authors and does not necessarily represent the official views of the funding bodies.

\section{Compliance with ethical standards}

Conflict of interest No conflict of interest to declare.

Open Access This article is distributed under the terms of the Creative Commons Attribution 4.0 International License (http://creativeco mmons.org/licenses/by/4.0/), which permits unrestricted use, distribution, and reproduction in any medium, provided you give appropriate credit to the original author(s) and the source, provide a link to the Creative Commons license, and indicate if changes were made.

\section{References}

1. Statistics South Africa (2017) General household survey 2017. http://www.statssa.gov.za/publications/P0318/P03182017.pdf. Accessed $14 \mathrm{Feb} 2018$

2. World Bank (1986) Poverty and hunger: Issues and options for food security in developing countries. http://documents.world bank.org/curated/en/166331467990005748/pdf/multi-page.pdf. Accessed 14 Feb 2018 
3. Food and Agriculture Organization of the United Nations (2013) Food and nutrition security should be the top development goal. http://www.fao.org/news/story/en/item/169830/icode/. Accessed $14 \mathrm{Feb} 2018$

4. Food and Agriculture Organization of the United Nations (2015) FAO and the post-2015 development agenda. http://www.fao. org/3/a-az775e.pdf. Accessed 14 Feb 2018

5. Weaver LJ, Hadley C (2009) Moving beyond hunger and nutrition: a systematic review of the evidence linking food insecurity and mental health in developing countries. Ecol Food Nutr 48:263-284

6. Jones AD (2017) Food insecurity and mental health status: a global analysis of 149 countries. Am J Prev Med 53:264-273

7. Statistics South Africa (2017) Poverty trends in South Africa: an examination of absolute poverty between 2006 and 2015. https:// www.statssa.gov.za/publications/Report-03-10-06/Report-03-10062015.pdf. Accessed 14 Feb 2018

8. Statistics South Africa (2018) Mid-year population estimates, 2018. http://www.statssa.gov.za/publications/P0302/P03022018. pdf. Accessed 14 Feb 2018

9. Statistics South Africa (2018) Quarterly labour force survey, quarter 2: 2018. http://www.statssa.gov.za/publications/P0211/P0211 2ndQuarter2018.pdf. Accessed 14 Feb 2018

10. Statistics South Africa (2016) Education series volume III: educational enrolment and achievement. http://www.statssa.gov.za/ publications/Report\%2092-01-03/Report\%2092-01-032016.pdf. Accessed 14 Feb 2018

11. Statistics South Africa (2017) Mortality and causes of death in South Africa, 2016: findings from death notification. http://www. statssa.gov.za/publications/P03093/P030932016.pdf. Accessed 14 Feb 2018

12. Jaramillo E, Sahu S, Van Weezenbeek C (2017) Ending TBrelated stigma and discrimination. Int J Tuberc Lung Dis 21:2-3

13. Rood EJ, Mergenthaler C, Bakker MI, Redwood L, Mitchell EM (2017) Using 15 DHS surveys to study epidemiological correlates of TB courtesy stigma and health-seeking behaviour. Int J Tuberc Lung Dis 21:S60-S68

14. Skinner D, Claassens M (2016) It's complicated: why do tuberculosis patients not initiate or stay adherent to treatment? A qualitative study from South Africa. BMC Infect Dis 16(1):712

15. Munro SA, Lewin SA, Smith HJ, Engel ME, Fretheim A, Volmink J (2007) Patient adherence to tuberculosis treatment: a systematic review of qualitative research. PLoS Med 4:e238

16. WHO. South Africa tuberculosis profile. https://extranet.who.int/ sree/Reports?op=Replet\&name=/WHO_HQ_Reports/G2/PROD/ EXT/TBCountryProfile \&ISO2=ZA\&outtype $=$ PDF. Accessed 14 Feb 2018

17. Statistics South Africa (2018) Mortality and causes of death in South Africa, findings from death notification. http://www.stats sa.gov.za/publications/P03093/P030932016.pdf. Accessed 14 Feb 2018

18. GBD 2015 (2016) Mortality and causes of death collaborators. Global, regional, and national life expectancy, all-cause mortality, and cause-specific mortality for 249 causes of death, 1980-2015: a systematic analysis for the Global Burden of Disease Study 2015. Lancet 388(10053):1459-1544

19. GBD 2015 DALYs and Hale Collaborators (2016) Global, regional, and national disability-adjusted life-years (DALYs) for 315 diseases and injuries and healthy life expectancy (HALE), 1990-2015: a systematic analysis for the Global Burden of Disease Study 2015. Lancet 388(10053):1603-1658

20. Straetemans M, Glaziou P, Bierrenbach AL, Sismanidis C, van der Werf MJ (2011) Assessing tuberculosis case fatality ratio: a meta-analysis. PLoS One 6:e20755

21. Ismail NA, Mvusi L, Nanoo A, Dreyer A, Omar SV, Babatunde S, Molebatsi T, van der Walt M, Adelekan A, Deyde V, Ihekweazu
C, Madhi SA (2018) Prevalence of drug-resistant tuberculosis and imputed burden in South Africa: a national and sub-national cross-sectional survey. Lancet Infect Dis 18(7):779-787

22. Pellowski JA, Barnett W, Kuo CC, Koen N, Zar HJ, Stein DJ (2017) Investigating tangible and mental resources as predictors of perceived household food insecurity during pregnancy among women in a South African birth cohort study. Soc Sci Med 187:76-84

23. Seedat S, Williams DR, Herman AA et al (2009) Mental health service use among South Africans for mood, anxiety and substance use disorders. S Afr Med J 99:346-352

24. Burns JK (2014) The burden of untreated mental disorders in KwaZulu-Natal Province-mapping the treatment gap. S Afr J Psychiatry 20:6-10

25. Chisholm D, Sweeny K, Sheehan P, Rasmussen B, Smit F, Cuijpers P, Saxena S (2016) Scaling-up treatment of depression and anxiety: a global return on investment analysis. Lancet Psychiatry 3(5):415-424

26. Williams DR, Herman A, Stein DJ, Heeringa SG, Jackson PB, Moomal $\mathrm{H}$ et al (2008) Twelve-month mental disorders in South Africa: prevalence, service use and demographic correlates in the population-based South African Stress and Health Study. Psychol Med 38(2):211-220

27. Evans-Lacko S, Knapp M (2016) Global patterns of workplace productivity for people with depression: absenteeism and presenteeism costs across eight diverse countries. Soc Psychiatry Psychiatr Epidemiol 51:1525-1537

28. Petersen I, Hancock JH, Bhana A, Govender K (2013) Closing the treatment gap for depression co-morbid with HIV in South Africa: voices of afflicted women. Health 5(3A):557-566

29. Seligman HK, Schillinger D (2010) Hunger and socioeconomic disparities in chronic disease. N Engl J Med 363:6-9

30. Hurst CE, Gibbon HMF, Nurse AM (2016) Social inequality: forms, causes, and consequences, 9th edn. Routledge, New York, p p387

31. Gundersen C, Gruber J (2001) The dynamic determinants of food insecurity. In: Andrews MS, Prell MA (eds) Second food security measurement and research conference, volume II: papers. Food assistance and nutrition research report no. 11-2. US Department of Agriculture-Economic Research Service, Washington, DC, pp 91-109

32. Noonan K, Corman H, Reichman NE (2016) Effects of maternal depression on family food insecurity. Econ Hum Biol 22:201-215

33. Garg A, Toy S, Tripodis Y, Cook J, Cordella N (2015) Influence of maternal depression on household food insecurity for low-income families. Acad Pediatr 15:305-310

34. Coates J, Swindale A et al (2007) Household Food Insecurity Access Scale (HFIAS) for measurement of food access: indicator guide (v.3). Washington, DC, Food and Nutrition Technical Assistance Project. Academy for Educational Development, Washington, DC, pp 18-32

35. Oketch JA, Paterson M, Maunder EW, Rollins NC (2011) Too little, too late: comparison of nutritional status and quality of life of nutrition care and support recipient and non-recipients among HIV-positive adults in KwaZulu-Natal, South Africa. Health Policy 99:267-276

36. Gordon N, Godfrey E, Aber JL, Richter L, SIZE Research Group (2007) Exploring patterns of receipt of cash grants, health care, and education among 7-10 year old children in KwaZulu-Natal, South Africa. Child Youth Serv Rev 78:177-188

37. Gibbs A, Carpenter B, Crankshaw T, Hannass-Hancock J, Smit J, Tomlinson M, Butler L (2017) Prevalence and factors associated with recent intimate partner violence and relationships between disability and depression in post-partum women in one clinic in eThekwini Municipality, South Africa. PLoS One 12:e0181236 
38. Maziya M, Mudhara M, Chitja J (2017) What factors determine household food security among smallholder farmers? Insights from Msinga, KwaZulu-Natal, South Africa. Agrekon 56:40-52

39. Sheehan DV, Lecrubier Y, Sheehan KH et al (1998) The miniinternational neuropsychiatric interview (M.I.N.I.): the development and validation of a structured diagnostic psychiatric interview for DSM-IV and ICD-10. J Clin Psychiatry 20:22-33

40. Senthilingam M, Pietersen E, McNerney R, te Riele J, Sedres P, Wilson R, Dheda K (2015) Lifestyle, attitudes and needs of uncured XDR-TB patients living in the communities of South Africa: a qualitative study. Trop Med Int Health 20(9):1155-1161

41. Akaike $H$ (1974) A new look at the statistical model identification. IEEE Trans Autom Control 19:716-723

42. Statistics South Africa (2018) National poverty lines. http://www. statssa.gov.za/publications/P03101/P031012018.pdf. Accessed 14 Feb 2018

43. Casey P, Goolsby S, Berkowitz C, Frank D, Cook J, Cutts D, Black MM, Zaldivar N, Levenson S, Heeren T, Meyers A (2004) Maternal depression, changing public assistance, food security, and child health status. Pediatrics 113:298-304

44. German L, Kahana C, Rosenfeld V, Zabrowsky I, Wiezer Z, Fraser D, Shahar DR (2011) Depressive symptoms are associated with food insufficiency and nutritional deficiencies in poor communitydwelling elderly people. J Nutr Health Aging 15:3-8

45. Laraia BA, Borja JB, Bentley ME (2009) Grandmothers, fathers, and depressive symptoms are associated with food insecurity among low-income first-time African-American mothers in North Carolina. J Acad Nutr Diet 109:1042-1047

46. Vogenthaler NS, Hadley C, Rodriguez AE, Valverde EE, Del Rio C, Metsch LR (2011) Depressive symptoms and food insufficiency among HIV-infected crack users in Atlanta and Miami. AIDS Behav 15:1520-1526

47. Alam K, Mahal A (2014) Economic impacts of health shocks on households in low and middle income countries: a review of the literature. Glob Health 10:21

48. Leive A, Xu K (2008) Coping with out-of-pocket health payments: empirical evidence from 15 African countries. Bull World Health Organ 86:849-856
49. Stop TB Partnership and Médecins Sans Frontières (2015) Out of step 2015-TB policies in 24 countries. https://www.health-e.org. $\mathrm{za} / \mathrm{wp}$-content/uploads/2016/01/report_out_of_step_2015_11_ pdf_with_interactive_links.pdf. Accessed 14 Feb 2018

50. Thase ME, Greenhouse JB, Frank E, Reynolds CF, Pilkonis PA, Hurley K, Grochocinski V, Kupfer DJ (1997) Treatment of major depression with psychotherapy or psychotherapy-pharmacotherapy combinations. Arch Gen Psychiatry 54:1009-1015

51. Gibbs A, Jewkes R, Willan S, Washington L (2018) Associations between poverty, mental health and substance use, gender power, and intimate partner violence amongst young (18-30) women and men in urban informal settlements in South Africa: a cross-sectional study and structural equation model. PLoS One 13(10):e0204956

52. Koyanagi A, Vancampfort D, Carvalho AF, DeVylder JE, Haro JM, Pizzol D et al (2017) Depression comorbid with tuberculosis and its impact on health status: cross-sectional analysis of community-based data from 48 low- and middle-income countries. BMC Med 15(1):209

53. Maharaj V, Tomita A, Thela L, Mhlongo M, Burns JK (2017) Food Insecurity and risk of depression among refugees and immigrants in South Africa. J Immigr Minor Health 19:631-637

54. Gundersen C, Kreider B, Pepper J (2011) The economics of food insecurity in the United States. Appl Econ Perspect Policy 33:281-303

55. MacCallum RC, Austin JT (2000) Applications of structural equation modeling in psychological research. Annu Rev Psychol $51: 201-226$

56. Masipa TS (2017) The impact of climate change on food security in South Africa: current realities and challenges ahead. Jamba 9:1-7

57. Connolly-Boutin L, Smit B (2016) Climate change, food security, and livelihoods in sub-Saharan Africa. Reg Environ Change 16:385-399 